\title{
The performances of Financial Models During COVID-19: Evidence from CAPM and Fama-French Five Factors Model
}

\author{
Yaxuan $\mathrm{Liu}^{1, *},{ }^{,}, \dagger$ Dingding $\mathrm{Xu}^{2, \mathrm{~b}, \dagger}$ \\ ${ }^{1}$ School of Management, Beijing Union University, Beijing, 100101, China \\ ${ }^{2}$ Main Campus, Western University, London, N6A 3K7, Canada \\ ${ }^{*}$ Corresponding author. Email: ${ }^{a} 21190111 @$ muc.edu.cn, ${ }^{b}$ dxu252@uwo.ca \\ ${ }^{\dagger}$ These authors contributed equally
}

\begin{abstract}
The ravages of the COVID-19 pandemic impact the operation of society, from home isolation to the shutdown of factories, bringing great uncertainty to the financial market. This article uses the information retrieval method to review the performance of the CAPM model and the Fama-French five factors model under the COVID-19 pandemic. As for the issue that CAPM has a weak ability to interpret abnormal data, many researchers have improved the CAPM model according to the real situation of different industries, but the improved model still has shortcomings. Moreover, there are differences in the performance of different industries in the Fama-French model before and after the pandemic. Specifically, interpretation strength has increased, and Mkt, SMB, HMI have changed significantly, but there are still unexplainable risk factors. Thus, future research should focus on how to further improve the interpretation of the model in response to emergencies to better explain and obtain excess returns. These results shed light on the better application of financial models in different situations.
\end{abstract}

Keywords: CAPM, Fama-French five factors, COVID-19

\section{INTRODUCTION}

Since the COVID-19 pandemic was first exposed in late 2019, it has rapidly spread and become a global pandemic. On 17 July 2021, WHO counted 190 million confirmed cases and more than 4 million COVID-19 pandemic deaths [1]. Due to the susceptibility and evolvable nature of COVID-19 strains, this pandemic will coexist with humans for a long time. The COVID-19 pandemic is a special black swan event, which has a certain reference value. Moreover, the pandemic is repetitive and long-term, which will directly impact society and financial markets and become a normal state. This would create incalculable dangers and serious uncertainties for the present and the future. The COVID-19 virus's ability to evolve and its long-term coexistence with humans means that the pandemic will still bring great uncertainty to the market. On this basis, it is significant to investigate whether the financial models are still valid under COVID-19. In fact, COVID-19 led to a sudden and violent shock to financial markets. To better prevent this from happening again, it is essential to investigate the effectiveness of models in the case of COVID-19.

Generally, there are two widely used models to evaluate financial assets: Capital asset pricing model (CAPM) [2] and Fama-French five factors model [3]. As the cornerstone of modern finance, CAPM describes the relationship between investment risk and expected return; the Fama-French five factors model is one of the most effective models to explain excess benefits. Therefore, we review the literatures that study their performance based on both models during the pandemic. This review report will summarize their performance in different industries from two models and make a comparative analysis.

\section{PERFORMANCES OF CAPM MODEL}

\subsection{Basic descriptions of CAPM}

The capital asset pricing model (CAPM) is the cornerstone of modern finance [2]. Based on Markowitz's portfolio theory, the model gives the price 
and rate of return when the stock market reaches equilibrium. CAPM can help people to invest in the concept of diversification more easily. CAPM consists of two types of risk in individual investment: systematic risk and unsystematic risk, which can be described mathematically as:

$$
E\left[R_{i}\right]=R_{f}+\beta_{s}\left(E\left[R_{m}\right]-R_{f}\right)
$$

where $E\left[R_{i}\right]$ means expected return of investment; $R_{f}$ means risk-free rate; $\beta_{\mathrm{s}}$ is a measure of systematic risk; $\left(E\left[R_{m}\right]-R_{f}\right)$ means market risk premium. Among these financial factors, $\beta_{\mathrm{s}}$ which is derived from a statistical analysis of individual daily stock price return rate and the market's daily returns over the same period is the only relevant measure of the volatility of a stock. This formula describes the relationship between investment risk and expected return. CAPM has two significant implications. First, CAPM provides a benchmark rate of return against which assets are valued. Second, this model helps investors to reasonably estimate the expected return rate of untraded assets. However, the validity of the model has been questioned under the COVID-19 pandemic. We will analyse specific industries and find the effectiveness factors of the model below [4].

CAPM is one popular financial model to determine the risk and return rate of the investment, which can help investors select stock and minimize risk. However, some scholars point out that CAPM may be insufficient to calculate the expected return of investment $\left(E\left[R_{i}\right]\right)$. For example, Maji [5] found that the $\beta$ of the BSE Sensex listed stocks fluctuated up and down from 2005 to 2008 when the market crashed. The $\beta$ sometimes has low predictive power.

The validity of the CAPM model has also been questioned under the COVID-19 pandemic because CAPM only uses one parameter $(\beta)$ to measure an investment's relative volatility. We will analyse specific industries and find the effectiveness factors of the model below.

\subsection{Performances of the stock market under the pandemic}

Many scholars have tested and analyzed CAPM under the COVID-19 pandemic. For example, Susanti, Grace, and Ervina [6] analyzed the relationship between $E\left[R_{i}\right]$ and $\beta$ of LQ 45 Index companies in detail. Except for extreme cases, they found that the beta value was inversely proportional to the value of $E\left[R_{i}\right]$. Besides, the higher the beta value, the lower the value of $E\left[R_{i}\right]$, and vice versa. Among the 45 companies, the accuracy of stock expectations was underestimated in 20 and undervalued in 25. As listed in Table 1, some companies have the problem of excessive deviation value
Table 1. Excessive deviation value of LQ 45 Index Shares collected from Ref. [6]

\begin{tabular}{|c|c|c|c|c|c|}
\hline $\begin{array}{l}\text { Issuer } \\
\text { Code }\end{array}$ & $R_{i}$ & $\begin{array}{r}E\left[R_{i}\right] \\
\mathrm{CAPM}\end{array}$ & Result & & Score \\
\hline ANTM & 0.1010 & -0.0408 & $\begin{array}{l}R_{i} \\
E\left[R_{i}\right]\end{array}$ & $>$ & Undervalued \\
\hline BRPT & 0.0167 & -0.0498 & $\begin{array}{l}R_{i} \\
E\left[R_{i}\right]\end{array}$ & $>$ & Undervalued \\
\hline ERAA & 0.0185 & -0.0510 & $\begin{array}{l}R_{i} \\
E\left[R_{i}\right]\end{array}$ & $>$ & Undervalued \\
\hline EXCL & 1.8603 & 0.1592 & $\begin{array}{l}R_{i} \\
E\left[R_{i}\right]\end{array}$ & $>$ & Undervalued \\
\hline PTBA & -0.0723 & 0.0014 & $\begin{array}{l}R_{i} \\
E\left[R_{i}\right]\end{array}$ & $<$ & Overvalued \\
\hline Tower & 0.3609 & -0.0317 & $\begin{array}{l}R_{i} \\
E\left[R_{i}\right]\end{array}$ & $>$ & Undervalued \\
\hline TBIG & 0.2446 & -0.0422 & $\begin{array}{l}R_{i} \\
E\left[R_{i}\right]\end{array}$ & $>$ & Undervalued \\
\hline
\end{tabular}

\subsubsection{Pharma industry}

Novel coronavirus affected the medical industry has become the focus of all disciplines in the world. Any decision made by the industry management and the progress of COVID-19 drug research brings uncertainty to stock market movements. No matter in the context of information or behavior, there was confusion and disorder in the pharma stock market in many places.

Considering the ongoing focus on the COVID-19 pandemic, Sinha and Agarwal [7] analyzed whether a reference-dependent version of CAPM was good at explaining and determining the pharma stocks' returns. They viewed CAPM with the prospect theory references. The prospect theory has three decision-references: certainty effect, reflection effect, and isolation effect. The report points out that the factors in CAPM, e.g., risk-free rate of return, the market rate of return, and the lagged endogenous rate of return, can be regarded as certainty effect, reflection effect, and isolation effect separately. A basic equation of CAPM with the prospect theory can be derived as:

$$
R_{i t}=\alpha_{0}+\alpha_{1} R_{f t}+\beta_{i t} R_{m t}+\varepsilon
$$

where $\mathrm{R}_{i t}$ is the return on investment $\mathrm{i}$ at time $\mathrm{t}$; $\mathrm{R}_{m t}$ is the return on the market portfolio at time $\mathrm{t}$; $R_{f t}$ is the risk-free rate at time t. Unlike Eq. (1), which uses the risk-free rate of return $\left(R_{f}\right)$ as a fixed value, Eq. (2) treats $R_{f t}$ as a separate variable and uses variable $\alpha_{0}$ as the intercept. Two alphas $\left(\alpha_{0}, \alpha_{1}\right)$ here are parameters that vary with the period and specific stock conditions. As one of the hottest investment industries after the outbreak of the COVID-19 pandemic, the stock market is greatly affected by government policies, the economic environment, and the pandemic situation. Therefore, this report adjusts the CAPM model more adaptable to volatile markets by adding a separate variable. 
They compared the pharma stocks' data on the NSE list before and during the COVID-19 pandemic and found that CAPM with the prospect theory Eq. (2) explained sample stocks in response to the reflection effect. However, the model cannot explain the certainty effect and isolation effect (as shown in Tables 1 and 2 in Ref. [7]). When using CAPM, investors need to use other models to increase its accuracies, such as the autoregressive distributed lag (ARDL) model and the generalized autoregressive conditional heteroskedastic (GARCH-X) model.

\subsubsection{Forest products industry}

The forest products industry is one of many industries affected by the COVID-19 pandemic. However, due to the diversification of the forest products industry sectors, the pandemic has different impacts on different forest products sectors. For example, the Food and Agriculture Organization [8] reports that the wood value chain has been severely hit, while the pulp and paper industry has remained positive during the pandemic. Moreover, the correlation between the forest products industry and the financial market is weak. In contrast, the forest products industry is affected more by global climate change, laws and regulations, policies, and other factors. This situation resulted in low systemic risk. Thus, in the face of the financial crisis of the pandemic, some forest product subsectors have suffered limited impacts.

Størdal, Lien, and Trømborg [9] studied the initial impact of the COVID-19 pandemic and lockdown on stock market returns of the forest products industry. To capture the effects of the sudden event, such as the COVID-19 pandemic, they conducted their report by the CAPM along the route of Mei and Sun [10]. The formula is:

$$
\begin{array}{r}
\mathrm{R}_{i t}-\mathrm{R}_{f t}=\alpha_{\mathrm{it}^{\sim}}+\beta_{\mathrm{it}^{\sim}}\left(\mathrm{R}_{m t}-\mathrm{R}_{f t}\right)+\mu_{i t} \mathrm{E}\left(\mu_{i t}=\right. \\
0), \text { and } \operatorname{var}\left(\mu_{i t}\right)=
\end{array}
$$$$
\sigma_{\mu_{t}}^{2}
$$

$\sigma_{\mu_{t}}^{2}$

where $\mathrm{t}^{\sim}$ is a rolling estimation of time, and the window length is 100 days; $\mathrm{R}_{i t}$ is the return on investment $\mathrm{i}$ at time $\mathrm{t} ; \mathrm{R}_{m t}$ is the return on the market portfolio at time $\mathrm{t} ; \mathrm{R}_{f t}$ is risk free rate at time $\mathrm{t} ; \alpha_{i \mathrm{it}^{-}}$is a measure of the abnormal return of investment with a rolling 100-day window; $\beta_{\mathrm{it}^{\sim}}$ is a measure of the systematic risk with a rolling 100-day window; $\mu_{i t}$ is the zero mean disturbance factor; $\mathrm{E}\left(\mu_{\mathrm{it}}=0\right)$ means the expected value of the zero mean disturbance factor. Compared with the original CAPM in Eq. (1), alpha and the concept of dynamic are applied in Eq. (3) for the special period of COVID-19 pandemic, which fully considers abnormal data in the sudden event. Additionally, it applied rolling estimates of CAPM, which let $\alpha$ and $\beta$ factors change over a predetermined period. The report states that the new model described by Eq. (3) can better reflect longer-term changes in stocks' returns and systemic risk caused by the COVID-19 pandemic. The window length cannot be too short to decrease the accuracy or too long to decrease the timeliness of results. The 100-day time period is suitable here to balance the two sides.
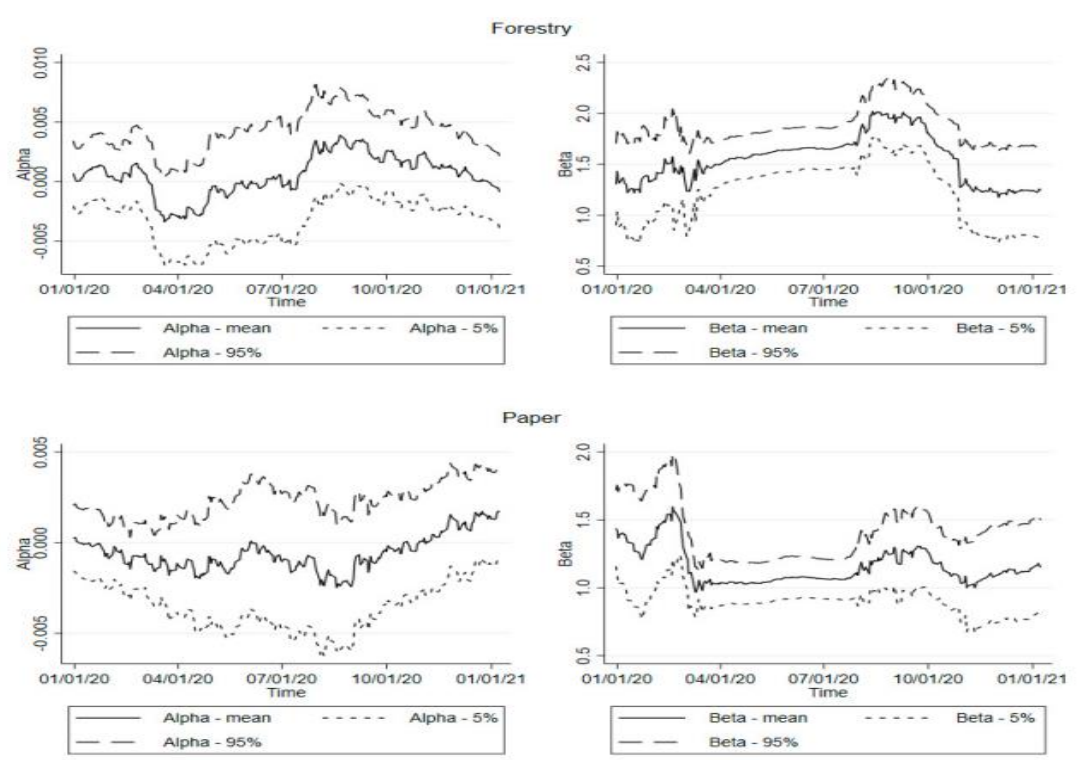

Figure 1. Comparison between alpha and beta factors from the rolling 100-day window [9]. The Solid lines are mean values, while dotted lines and dash lines are 5\% and 95\% confidence levels, respectively

According to the Eq. (3), Størdal, Lien, and Trømborg [9] studied the development of $\alpha_{i t^{\sim}}$ and $\beta_{i t^{\sim}}$ factors for the forestry and the paper subsectors (as shown Fig. 1). The result is that systemic risk $(\beta)$ in the 
forestry subsector is likely to increase during 2020, with North America the most obvious. In contrast, the paper subsector showed little change. The forestry subsector is more volatile than the paper subsector and is more affected by catastrophic events. Compared with the obvious difference and change of $\beta$ value, the $\alpha$ value of the forestry and the paper subsector is basically 0 . Therefore, through practical analysis, they found that paper production was capital-intensive and showed continuous production while the forestry subsector of sawn wood showed strong periodicity.

\subsection{Comparison and analysis}

The COVID-19 pandemic has affected many industries to varying degrees. The accuracy of financial estimation results obtained by the CAPM model as a sudden COVID-19 pandemic is greatly reduced because the original CAPM (Eq. (1)) does not consider abnormal values. The two reports about the pharma industry and the forest products industry make adjustments to the original Eq. (1) based on their own market circumstances to avoid this situation. Eq. (2) in the report of the pharma industry adds independent variables, while Eq. (3) of the forest products industry adds the abnormal return of investment and the concept of dynamics.

However, the formulas tweaked by the two industries still fall short. The CAPM with the prospect theory (Eq. (2)) used in the pharma industry's report cannot be analyzed and explained reflection effect and isolation effect. ARDL model, GARCH-X model, and other models should be used to supplement the description of these two decision-references. For the forest products industry (Eq. (3)), the $\alpha$ value fluctuates somewhat. However, the value is very small and basically close to zero, i.e., it plays a very limited role here.

In general, it is good to adjust CAPM for different industries, but the formula should conform to the situation of each industry. It is hoped that researchers can further adjust the formula based on the existing achievements in the future.

\section{PERFORMANCES OF FAMA-FRENCH FIVE FACTORS MODEL}

\subsection{Basic descriptions of Fama-French models}

CAPM states that market risk is the only risk that may bring excess returns to stocks. However, the empirical results show that this cannot explain the difference in stock portfolio returns well. It may even cause damage to the economic market, leading to an aggravation of the financial crisis. Therefore, Fama-French (1993) [11] proposed to add SMB risk and book-to-SMB ratio risk based on the CAPM model to measure its returns, avoiding most of the anomalies of CAPM and called it the "Fama-French three-factor model", which can be described mathematically as:

$r_{i}-r_{f}=\alpha_{i}+\beta_{m k t}\left(r_{m k t}-r_{f}\right)+\beta_{S M B} E_{S M B}+\beta_{H M I} E_{H M I}+\varepsilon_{i}$

where $r_{i}$ is the total return of a stock or portfolio; $r_{f}$ represents the return on risk-free assets; $\left(r_{i}-r_{f}\right)$ represents the expected excess return of a stock; $\alpha_{i}$ represents the constant of the model; $\beta_{m k t}$ is the factor of the market risk-free interest rate sensitivity of the rate of return of investment relative to the market, that is, the risk load; $r_{m k t}$ is the total market portfolio return; $\left(r_{m k t}-r_{f}\right)$ describes the excess return of the market investment portfolio, which is the market risk of uncertainty caused by the market trend; $\beta_{S M B}$ is the coefficient of the company's size, and $E_{S M B}$ represents the expected excess return rate of a small market capitalization company relative to the stocks of a large market capitalization company, the scale premium; $\varepsilon_{i}$ is the residual regression term.

With the continuous improvement of the financial market, many scholars have discovered some phenomena that the average return rate of stocks with higher expected cash flow is higher, and there is an obvious relationship between profitability and investment-related average return. Hence, Fama-French proposed five factors [3], as follows.

$r_{i}-r_{f}=\alpha_{i}+\beta_{m k t}\left(r_{m k t}-r_{f}\right)+\beta_{S M B} E_{S M B}+\beta_{H M I} E_{H M I}+\beta_{R M W} E_{R M W}+$

$\beta_{C M A} E_{C M A}+\varepsilon_{i}$

where $\beta_{H M I}$ represents the coefficient of the book-to-SMB ratio, and $E_{H M I}$ is the expected excess return between high $\mathrm{B} / \mathrm{M}$ (owner's equity divided market capitalization) company stocks and low B/M company stocks; $\beta_{R M W}$ is the coefficient of profitability, and $E_{R M W}$ represents the difference between the returns of high-profit and low-profit stock portfolios; $\beta_{C M A}$ is the coefficient of investment value; $E_{C M A}$ represents the difference between the return of a low reinvestment ratio and a high reinvestment ratio stock portfolio, that is, the company's ability to expand reproduction.

However, this model also has certain limitations. The Fama-French five factors model is empirical, lacks the support of systematic theoretical. Besides, it has two major premises: theoretical and statistical assumptions. Some scholars, such as Foye [12], have found that it cannot explain the phenomenon that small market capitalization stocks with low profitability and more investment will have lower-than-average returns. Certain factors are not significant in the Asian market. Nevertheless, the Fama-French five factors model is still one of the best explanations for the excess risk. 


\subsection{Excess returns under the pandemic}

\subsubsection{Stock market}

Predicting the return of stocks is one of the most important issues in the financial market. The pandemic has had a significant impact on financial markets around the world. Many scholars have suspected whether the Fama-French five factors model can effectively explain the excess returns in the stock market under the extreme circumstances of the pandemic.

After fitting the curve, Horváth found that the $\mathrm{R}^{2}$ during the pandemic had dropped significantly, and its curve was similar to the 2009-2013 Debt crisis curve (as shown in Fig. 2) [13]. According to the results, the impact of the pandemic and the debt crisis on the financial market is similar. The decline in the degree of fitness indicates that the Fama-French model's interpretation of excess returns has decreased, and other risks cause excess risks. Besides, based on ordinary least squares (OLS), Horváth also found that all five factors of the five factors model have declined, and growth in investment portfolios and growth companies will bring excess returns. However, Sun's subsequent research found that $\mathrm{R}^{2}$ showed an upward trend in a longer observation period, i.e., the Fama-French five factors model's ability to explain the industry's excess returns has increased, which has a positive impact [14]. Nevertheless, the Fama-French model has poor performance in residual analysis. After the pandemic outbreak, it increased from 11 industries to 38 industries that failed the ARCH test. The outbreak of the pandemic may have brought some undiscovered or difficult factors to explain.

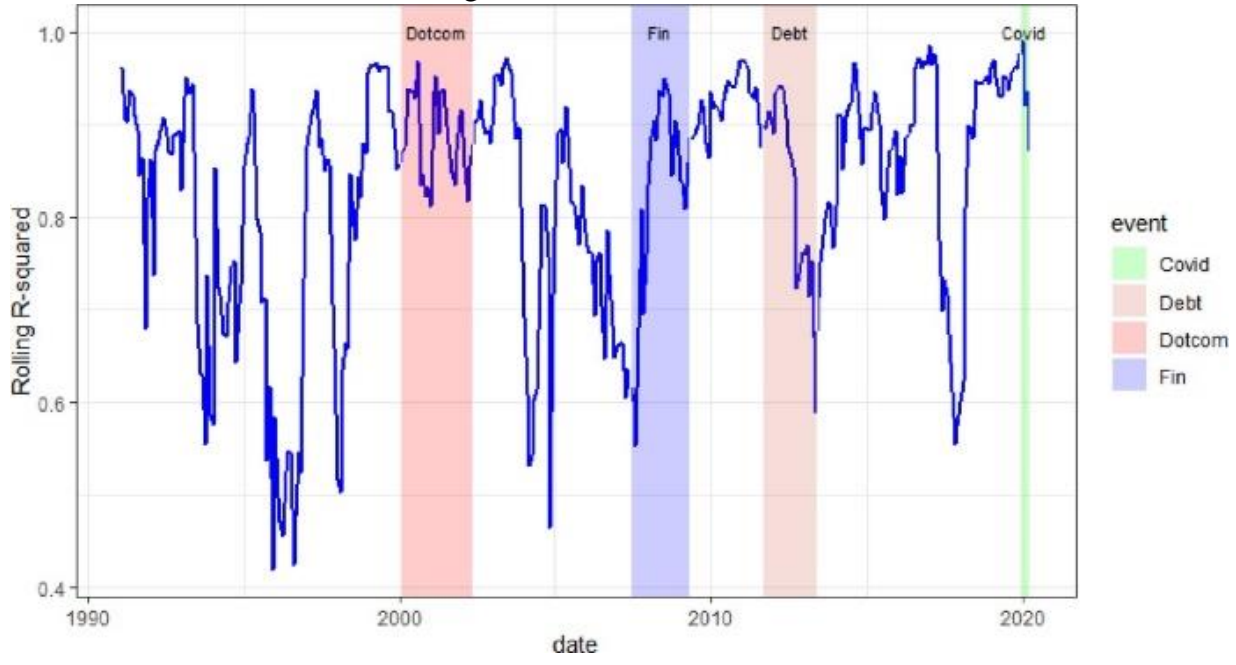

Figure 2 The impacts of selected events on $\mathrm{R}^{2}$ [13].

Some scholars have studied the impact of policies on stock returns during the pandemic. Among them, Bannigidadmath uses the Fama-French model to calculate the abnormal income of each country's stocks during the pandemic five days before and after the incident [15]. According to the results, stock returns have a negative impact before the policy is implemented, and the travel ban has the least impact. The variable value shows the effectiveness of the Fama-French five factors model under pandemic conditions.

\subsubsection{Excess earnings of different industries under the pandemic}

Due to its peculiar nature, the pandemic will have large impacts on various industries. First of all, the pandemic is different from the financial stock crisis. It only directly impacts the financial industry but has an indirect effect on the financial market through entity industry. Secondly, the highly contagious nature of the pandemic affects people's travel and daily work and will have a deeper impact on labor-intensive industries. Therefore, different industries will be affected differently in the general environment of the pandemic.

\subsubsection{Steel industry}

The steel industry is representative of labor-intensive industries and requires a lot of manpower to complete. Hou [16], based on the Fama-French five factors model (FF5), this paper analyzes the market changes of the American steel industry before and after the pandemic (listed in Table. 2) 
Table 2. Coefficient of 5-factor model of steel industry before and after the pandemic

\begin{tabular}{c|cc|cc|cc|ccc}
\hline & Coefficient & Coefficient* & Std & Std* & t Stat & t Stat* & P-value & P-value* \\
\hline mkt & 1.04 & 0.91 & 0.06 & 0.04 & 16.62 & 25.95 & 0 & 0 \\
SMB & 1.15 & 0.99 & 0.12 & 0.1 & 9.81 & 10.343 & 0 & 0 \\
HML & 0.46 & 0.45 & 0.12 & 0.08 & 3.82 & 5.77 & 0 & 0 \\
RMW & 0.46 & 0.28 & 0.2 & 0.16 & 2.35 & 1.72 & 0.02 & 0.09 \\
CMA & 0.21 & -0.08 & 0.23 & 0.22 & 0.9 & -0.38 & 0.37 & 0.7 \\
\hline
\end{tabular}

Note: * represent after the pandemic.

It can be seen from the market factor coefficient that the US steel industry is very sensitive to economic fluctuations throughout the entire market. The pandemic has caused the closure of factories in the automobile and other industries, which has caused a decline in steel consumption. Moreover, the shutdown of the pandemic has also led to a decline in production. The coefficient of HMI factors has dropped significantly, and industrial stagnation has led to a slowdown in demand, which has seriously affected the steel industry's profitability. The SMB factor coefficient and the HMI factor coefficient declined slightly before and after the pandemic, indicating that the pandemic has a significant impact on the market value of the steel industry. The CMA factor coefficient is not significant before and after the pandemic and is closely related to the development of the steel industry. This also indicates that investors in the steel industry have a higher demand for output.

\subsubsection{Pharma industry}

The global spread of COVID-19 has caused severe economic and social impacts and has also made the

Table 3. Coefficients of the five-factors model of the pharma industry before and after the pandemic

\begin{tabular}{ccccccc}
\hline Time & Parameter & Mkt & SMB & HML & RMW & CMA \\
\hline \multirow{2}{*}{$2019.07-2020.02$} & Coefficient & $0.94^{*}$ & $1.28^{*}$ & $-0.35^{*}$ & $-0.78^{*}$ & 0.12 \\
& t Stat & 17.43 & 11.80 & -3.30 & -4.35 & 0.55 \\
$2020.03-2020.10$ & Coefficent & $0.94 *$ & $0.93^{*}$ & $-0.29^{*}$ & $-1.13^{*}$ & 0.06 \\
& t Stat & 35.40 & 12.80 & -4.90 & -9.30 & 0.37 \\
\hline
\end{tabular}

Note: $*$ represents the significance

\subsection{Comparison and analysis}

The Fama-French five factors model has different interpretation effectiveness for the excess risk of two industries with different market performance. Among the two industries described above, the pharma industry is superior due to its high demand during the pandemic. In contrast, the steel industry is a disadvantaged industry due to its lack of on-site labor.

In the Fama-French five factors model, the CMA factors of the two industries are not significant, and the excess return is mainly affected by market risk, SMB, and RMW factors. The SMB factor of the steel industry becomes redundant after the pandemic, and excess returns are mainly affected by the other three factors. Comparing the five factors of the two industries, there market aware of the great value of pharma companies. It is one of the few favorable industries in this pandemic. In the context of the pandemic, whether the rise in the US stock market pharma industry conforms to the Fama-French five factors model has also become a concern of many scholars.

$\mathrm{Li}$ and Zhang investigated the changes in the US pharma industry before and after the pandemic [17]. The results demonstrate that the model's interpretation strength $\mathrm{R}^{2}$ has been enhanced after the pandemic. Before and after the pandemic, the five factors have not changed much (as shown in Table 3). The overall market factors have changed a little. The SMB factor and RMW factor coefficients have declined slightly, the HMI factor coefficients have risen, and the RMW factor has been redundant. Therefore, the "small-scale" effect of the pharma industry and the characteristics of growth stocks tend to be more significant. The characteristics are more obvious, and the entire industry has a certain degree of speculation. 
pandemic and is less affected by the pandemic. The most influential risk factors in different industries have changed before and after the pandemic, indicating that the explanatory power of the Fama-French five factors model has increased, which can produce significant model performance differences.

In addition to these two clearly representative industries, Sun has studied whether there are unexplainable factors in the excess risk of 49 industries in the United States before and after the pandemic and whether they have changed due to the impact of the pandemic. [14] As depicted in Fig. 3, Mkt, SMB, and HMI factors fell sharply after the pandemic. In contrast, profitability and investment factors have remained stable, and no industry has avoided the decline in asset prices in the entire market. This figure once again supports the dominant position of market risk in the model. There was a large degree of fluctuation before and after the pandemic. The curves of RMW and HMI are relatively flat, and the impact of the pandemic is limited. Sun found that only a few industries did not find residual anomalies in the Fama-French five factors model, indicating that the Fama-French five factors model did not have sufficient explanatory power to explain the random fluctuations of asset prices in most industries portfolios.

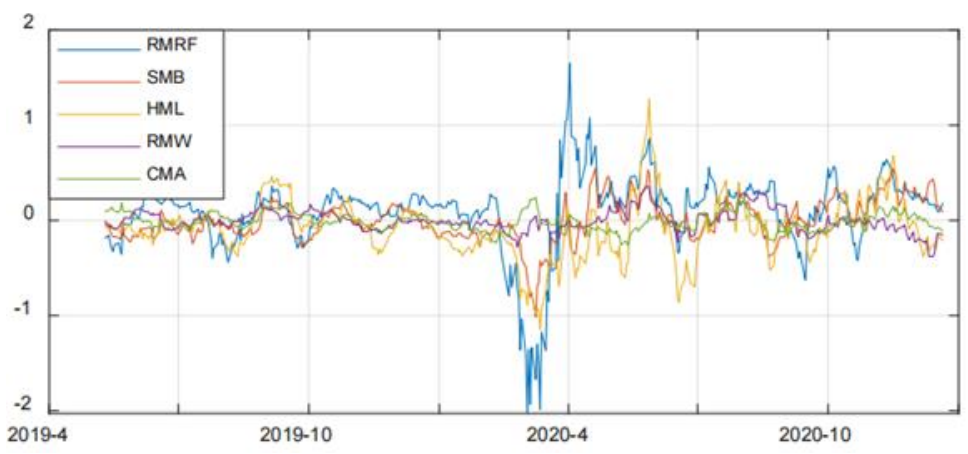

Figure 315 Days Rolling Moving-Average of Fama-French Factors [14].

In a nutshell, the current literature on the performance of FF5 in the pandemic describes the increased interpretation in multiple industries in more detail. However, there is still a lot of room for research. First of all, researchers lack a thorough study of the change of five factors since the rule of changes is important for future emergencies. Secondly, there is no further study of the unexplained risks that still exist, and it is impossible to determine whether they are the risks arising from a pandemic or the inherent risks. Finally, the pandemic is still underway, and there may be variables in the future that require ongoing research.

\section{CONCLUSION}

In summary, we review the performance of models in different industries after the COVID-19. Specifically, as the CAPM model is weak in responding to sudden events such as the COVID-19 pandemic, many improved models have been proposed to better adapt to the needs of different industries. The advantages and disadvantages of the new models were analyzed by taking the pharma industry and the forest products industry as examples. The new model for the pharma industry adds a separate variable and the new model for the forest products industry adds the dynamic concept. However, the two new models are still insufficient for their own industries. With regard to the Fama-French five factors model, the model's interpretation of excess stock returns in multiple industries has increased. Take the pharma industry and the steel industry as examples.
Among them, SMB, HMI, and Mkt have changed significantly before and after, which are greatly affected by the pandemic, i.e., highlight the model's interpretation effect. However, there is still unexplainable risk whether it is related to emergencies remains to be studied.

According to our results, the analysis of financial model performance is phased because the pandemic is still ongoing. The number of industries studied is limited. Additionally, only studied the performance without giving a practical solution. Thus, researchers will be able to analyse more industries by using financial models hopefully. Meanwhile, it is hoped that researchers can continue to pay attention to the model's effectiveness during the pandemic in the future, i.e., suggest further modifications of models. These results offer guidelines for confronting similar black swan incidents. It provides a reference and contributes to the stability of the market in the future.

\section{REFERENCES}

[1] Li, X., Li, A. J., \& Du, B. (2021). COVID-19. Stem Cell Research, 55, 102468.

[2] Sharpe, W. F., G. J. Alexander \& J. V. Bailey (1999), Investments, Englewood Cliffs, NJ: Prentice Hall International, 6th edition. 
[3] Fama, E. F., \& French, K. R. (2015). A five factors asset pricing model. Journal of financial economics, 116(1), 1-22.

[4] Bailey, R. (2005). Economics of financial markets. ProQuest Ebook Central.

[5] Maji, K., 2010. Validity of Capital Asset Pricing Model \& Stability of Systematic Risk (Beta): An Empirical Study on Indian Stock Market. SSRN Electronic Journal.

[6] Susanti, E., Ernest Grace, \& Nelly Ervina. (2020). The investing decisions during the Covid-19 PANDEMIC by using the capital asset pricing Model (CAPM) method in lq 45 INDEX COMPANIES. International Journal of Science, Technology \& Management, 1(4), 409-420.

[7] Sinha, P. C., \& Agarwal, P. (2021). COVID-19 and CAPM: a tale of reference dependence with the pharma stocks' returns. Theoretical \& Applied Economics, 28(2).

[8] FAO. 2020. Impacts of COVID-19 on Wood Value Chains and Forest Sector Response: Results from a Global Survey 2020. Rome: Food and Agriculture Organization.

[9] Størdal, S., Lien, G., \& Trømborg, E. (2021). Impacts of Infectious Disease Outbreaks on Firm Performance and Risk: The Forest Industries during the COVID-19 Pandemic. Journal of Risk and Financial Management, 14(7), 318. MDPI AG.

[10] Mei, Bin, \& Changyou Sun. 2008. Event analysis of the impact of mergers and acquisitions on the financial performance of the U.S. forest products industry. Forest Policy and Economics 10: 296-94.

[11] Fama, E. F., \& French, K. R. (1993). Common risk factors in the returns on stocks and bonds. Journal of Financial Economics, 33(1), 3-56.

[12] Foye, J. (2018). A comprehensive test of the Fama-French five factors model in emerging markets. Emerging Markets Review, 37, 199-222.

[13] Horváth, D., \& Wang, Y.-L. (2021). The examination of Fama-French Model during the Covid-19. Finance Research Letters, 41, 101848.

[14] Sun, Y. (2021, April 12). Analysis of fore and aft covid-19 impact on industry data based on fama-french five factors. Web of Proceedings Francis Academic Press.

[15] Bannigidadmath, D., Narayan, P. K., Phan, D. H., \& Gong, Q. (2021). How stock markets reacted to COVID-19? Evidence from 25 countries. Finance Research Letters, 102161.
[16] Hou, D., \& Chen, Z. (2021). Research on the application of Fama-French 5-factor model in the steel industry during COVID-19. Journal of Physics: Conference Series, 1865(4), 042104.

[17] Li Shuai, D., \& Zhang Qiang. (2021) Empirical research and regulatory thinking on the pharmaceutical industry in the U.S. stock market under the new crown pandemic_-Based on the Fama-French three-factor and five factors model. Market Forum, 2021(01):76-8 